\title{
Fate of infants with transposition of the great arteries in relation to balloon atrial septostomy
}

\author{
TEYRNON G POWELL, MICHAEL DEWEY, CHRISTOPHER R WEST, ROBERT ARNOLD \\ From the Regional Paediatric Cardiothoracic Unit, Royal Liverpool Children's Hospital, and the Biostatistics Unit, \\ University of Liverpool, Liverpool
}

SUMMARY The palliation afforded by balloon atrial septostomy to 124 infants with transposition of the great arteries was assessed in terms of survival to 6 months of age without the need for further intervention. Prediction of success or failure in relation to palliation was significantly affected by the presence of associated ventricular septal defect, left ventricular outflow tract obstruction, or persistent ductus arteriosus and by the maximum volume of balloon used to perform the septostomy. There was a significant association between balloon volume and size of atrial defect found at subsequent surgery or necropsy.

The results of definitive surgery for infants with transposition of the great arteries are optimal beyond 6 months of age at our centre, ${ }^{1}$ so that the management of such infants will depend on the increased risks of earlier surgery and the risks of the waiting period before surgery. Most of these infants die before 6 months of age without palliation, ${ }^{2}$ whereas balloon atrial septostomy ${ }^{3}$ has allowed the majority to survive to this age. Reports of the results of septostomy show a varying cumulative morbidity and mortality before definitive surgery despite this procedure, ${ }^{4-20}$ although an improvement has taken place more recently. ${ }^{21} 22$ Balloon septostomy catheters that can provide larger effective balloon volumes than those used when the procedure was first introduced are now available, and that, together with other factors, may have contributed to the improved survival figures also seen at our centre.

In this study we assessed the importance of balloon volume used at septostomy and the morbidity and mortality before definitive surgery of infants with transposition of the great arteries after a technically adequate septostomy had been performed.

\section{Patients and methods}

Case records of all infants with transposition of the great arteries managed at this hospital who underwent

Requests for reprints to Dr $\mathbf{R}$ Arnold, Regional Paediatric Cardiothoracic Unit, Royal Liverpool Children's Hospital, Myrtle Street, Liverpool L7 7DG.

Accepted for publication 25 October 1983 their first balloon septostomy between 1 January 1968 and 1 January 1980 were examined. Ten cases were excluded since the records did not include data on septostomy balloon volumes. Only infants with atrioventricular concordance, ventriculoarterial discordance, and normal pulmonary and systemic venous connections were included. Data extracted from case records are shown in Table 1 . The information was processed on the University of Liverpool IBM computer. Where possible data were entered as actual values; coded variables are as shown.

\section{CODING OF VARIABLES}

The presence of a large ventricular septal defect was coded if a defect of over $3 \mathrm{~mm}$ was measured either at surgery or necropsy and, where such data were not available, if angiographic appearances suggested a defect of over $3 \mathrm{~mm}$. Other defects were coded as small. A persistent ductus arteriosus was coded as large if it was described as large at surgery or necropsy of if the pulmonary artery to aortic systolic pressure ratio was above $0 \cdot 8$. A ductus present at initial catheterisation which was shown to have closed spontaneously at subsequent study or surgery was coded as absent. Left ventricular outflow tract obstruction was regarded as absent if the systolic pressure gradient between pulmonary artery and left ventricle was $<20$ $\mathrm{mm} \mathrm{Hg}$, as mild between 20 and $35 \mathrm{~mm} \mathrm{Hg}$, as moderate between 35 and $60 \mathrm{~mm} \mathrm{Hg}$, and as severe either if $>60 \mathrm{~mm} \mathrm{Hg}$ or if the left ventricular pressure was suprasystemic. Cases with left ventricular systemic pressure of $<40 \mathrm{~mm} \mathrm{Hg}$ were graded as having no obstruction, and those in which such data were not 
Table 1 Coding and frequency of variables ( $n=$ number of observations)

\begin{tabular}{|c|c|c|c|c|c|}
\hline \multirow[t]{2}{*}{ Variables } & \multicolumn{4}{|l|}{ Coding } & \multirow[t]{2}{*}{$n$} \\
\hline & 1 & 2 & 3 & 4 & \\
\hline $\begin{array}{l}\text { Coded: } \\
\text { Sex } \\
\text { Ventricular septal defect } \\
\text { Persistent ductus arteriosus } \\
\text { Left ventricular outflow tract obstruction } \\
\text { Coarctation } \\
\text { Thrombosis } \\
\text { Defect size } \\
\text { Death by age } 6 \text { months } \\
\text { Second procedure by aged } 6 \text { months } \\
\text { Uncoded: }\end{array}$ & $\begin{array}{l}\text { Male } \\
\text { Absent } \\
\text { Absent } \\
\text { Absent } \\
\text { Absent } \\
\text { No } \\
\text { Small } \\
\text { Yes } \\
\text { Yes }\end{array}$ & $\begin{array}{l}\text { Female } \\
\text { Small } \\
\text { Small } \\
\text { Mild } \\
\text { Present } \\
\text { Yes } \\
\text { Medium } \\
\text { No } \\
\text { No }\end{array}$ & $\begin{array}{l}\text { Large } \\
\text { Large } \\
\text { Moderate } \\
\text { Large }\end{array}$ & $\begin{array}{l}\text { Ligated } \\
\text { Severe }\end{array}$ & $\begin{array}{r}124 \\
124 \\
124 \\
94 \\
124 \\
124 \\
90 \\
124 \\
124\end{array}$ \\
\hline $\begin{array}{l}\text { Oxygen saturation before balloon atrial septostomy } \\
\text { Oxygen saturation after balloon atrial septostomy } \\
\text { Oxygen saturation rise } \\
\text { Maximum balloon volume } \\
\text { First pull volume } \\
\text { Age at balloon atrial septostomy } \\
\text { Age at second study } \\
\text { Oxygen saturation at second study } \\
\text { Haemoglobin concentration at second study } \\
\text { LA pressure at second study } \\
\text { RA pressure at second study } \\
\text { PA pressure at second study } \\
\text { LV pressure at second study }\end{array}$ & & $\ddots$ & & & $\begin{array}{r}71 \\
68 \\
60 \\
124 \\
68 \\
124 \\
87 \\
72 \\
74 \\
61 \\
62 \\
35 \\
67\end{array}$ \\
\hline
\end{tabular}

LA, left atrial; RA, right atrial; PA, pulmonary artery; LV, left ventricular.

recorded were graded according to angiographic, surgical, or necropsy findings where available. Infants who underwent pulmonary artery banding were coded according to findings at subsequent study.

Maximum balloon volume used to perform the first septostomy procedure was recorded as the maximum volume of contrast fluid used to inflate the balloon. The balloon volume used for the first attempt to tear the septum during the first septostomy procedure was also noted.

Since we aimed to determine the efficacy of the technique of septostomy in terms of palliation we defined success of septostomy as survival after initial septostomy to 6 months of age without any further palliative or definitive procedure other than surgery for associated anomalies. Failures were coded either as deaths before 6 months of age or as second procedures before 6 months of age.

The diameters of 83 atrial defects resulting from the first septostomy had been recorded either at necropsy or at surgery. Diameters of a further seven defects were measured from necropsy specimens stored in formalin; no allowance was made for shrinkage. Defects resulting from repeat septostomy or other procedures were ignored.

The relation between data available at the time of septostomy and failure of palliation was analysed by logistic regression, ${ }^{23}$ thus enabling intercorrelated variables to be analysed simultaneously.
CLINICAL DATA

Of 124 infants, $92(74 \%)$ were male and $32(26 \%)$ were female. Age at septostomy ranged from day 1 to day 131 (median day 5, mode day 2); six septostomies were performed after the fifth week of life. Weight at septostomy ranged from 2.0 to $7.9 \mathrm{~kg}$ (median and mean $3.47 \mathrm{~kg}$ ).

Eighty three (67\%) infants had an intact ventricular septum, $13(10 \%)$ had a small ventricular septal defect, and $28(23 \%)$ a large defect. Ninety five (77\%) had no persistent ductus arteriosus; $12(10 \%)$ a small ductus, seven (6\%) a large ductus, and $10(8 \%)$ a ligation performed. Left ventricular outflow tract obstruction was absent in $58(62 \%)$, mild in $19(20 \%)$, moderate in $12(13 \%)$, and severe in five $(5 \%)$. Aortic coarctation was found in nine (7\%) cases.

Systemic arterial oxygen saturation before septostomy ranged from $17 \%$ to $85 \%$ (median $60 \%$ ). Immediately after septostomy, the range was $35 \%$ to 95\% (median 76\%).

Maximum balloon volume ranged from 1.5 to 6.0 $\mathrm{ml}$ (median $2.2 \mathrm{ml}$, mean $2.9 \mathrm{ml}$, mode $2 \mathrm{ml}$ ). First pull volumes ranged from 1 to $4 \mathrm{ml}$ (median $1.8 \mathrm{ml}$ ).

\section{SECOND STUDY}

A second study was performed between the first and fifty-ninth month in 87 cases (median seventh month). Median arterial oxygen saturation was $64 \%$ (range 23-85\%). Haemoglobin concentration ranged 
from 11.8 to $25.2 \mathrm{~g} / \mathrm{dl}$ (median $18.9 \mathrm{~g} / \mathrm{dl}$ ). As a result of a single septostomy in 90 cases, there were 40 large defects ( $\geqslant 15 \mathrm{~mm}$ diameter), 27 moderate sized defects $(10-14 \mathrm{~mm})$, and 23 small defects $(<10 \mathrm{~mm})$. There were $60(48 \%)$ failures of initial septostomy, including 38 (31\%) who died before 6 months of age and $35(28 \%)$ who underwent a second palliative procedure before 6 months of age.

\section{Results}

Factors known at the time of balloon septostomy were analysed in terms of their relation to failure of palliation. Since several of these predictor variables may be intercorrelated, it is most appropriate to analyse them simultaneously. This was achieved by predicting the probability of failure of palliation using logistic regression analysis.

The final set of predictor variables used satisfied the criterion that the inclusion of a variable in the regression equation should lead to a significant reduction in deviance. The following variables failed to meet this criterion and were thus not considered to have a significant predictive effect: age at septostomy, weight, sex, presence of coarctation, and systemic oxygen saturations before and immediately after septostomy.

The final equation used was:

Il $(\mathrm{p} / 1-\hat{\mathrm{p}})=1.30-0.843(\mathrm{MBV})+\mathrm{a}+\mathrm{b}+\mathrm{c}$ where $M B V$ is maximum balloon volume ( $\mathrm{ml}) ; \mathrm{a}=0$ if ventricular septal defect was absent, 1.19 if small, -1.61 if large; $b=0$ if persistent ductus arteriosus was absent, 2.78 if small, 1.90 if ligated, 1.96 if large; $c=$ 0 if left ventricular outflow tract obstruction was absent, -0.60 if mild, 1.99 if moderate, 1.72 if severe, 2.70 if unknown. This equation enabled failure (estimated $\mathrm{p}>0.5)$ to be correctly predicted in $100(81 \%)$ cases.

There was a trend towards increasing success of palliation in the later years of the study, the most notable difference between year groups being between 1968-75 and 1976-79 $(\mathrm{p}<0.001)$. Adding the year of septostomy to the regression equation did not, however, yield a further significant reduction of deviance. Thus we were unable to show any improvement in success of palliation in more recent years over and above that explained on the basis of increased balloon volume. Maximum balloon volumes of over $3 \mathrm{ml}$ were exclusive to the years 1976-79. Further comparison of year groups showed that there was a higher incidence of recorded ventricular septal defects and left ventricular tract obstruction in 1976-79 $(p<0.05)$, presumably from increased accuracy of diagnosis. There was an almost significant decrease in the incidence of major thrombosis (thrombosis of the inferior vena cava or its major branches or a cerebrovascular acci-
Table 2 Failure and mortality in relation to presence of persistent ductus arteriosus, maximum balloon volume, and defect size

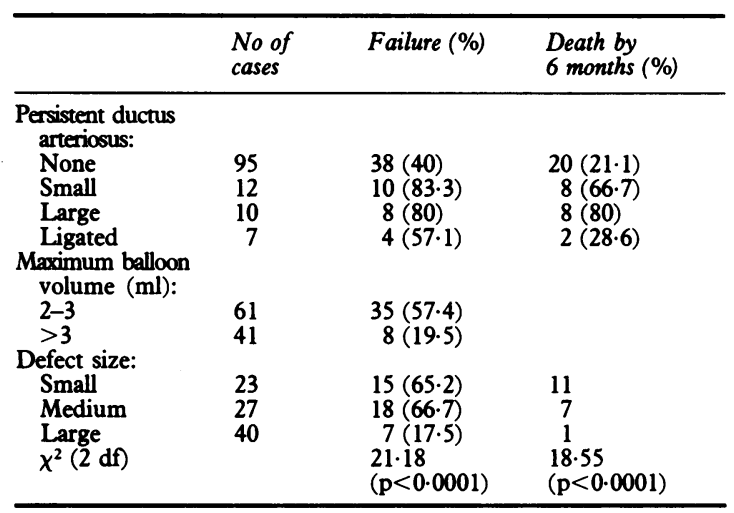

dent) in 1976-79 compared with 1968-75 ( $\mathrm{p}=0.06)$.

A persistent ductus arteriosus whether small or large had a deleterious effect. The relation between the presence of a persistent ductus and failure and mortality at 6 months of age is shown in Table 2 .

The relation between left ventricular outflow tract obstruction and failure varied according to the degree of obstruction, mild degrees having a beneficial effect. Similarly, the presence of a large ventricular septal defect had a beneficial effect, although this was not true of a small defect.

There was a positive correlation between maximum balloon volume and first pull volume so that their effects on failure could not be separated, although the effect of maximum balloon volume appeared to be the greater. Failure rate was lower for volumes of over 3 $\mathrm{ml}$ than for those of 2-3 ml.

\section{DEFECT SIZE}

There was a significant rank association between maximum balloon volume and defect size, larger balloons being associated with larger defects $(p=0.001)$. Defect size had no significant relation to age or weight at septostomy, the presence of associated defects, or systemic oxygen saturation changes at first study. There was a significant association between defect size and failure or mortality at 6 months (Table 2 ).

The second study was performed at an earlier age with smaller defects $(p=0.04)$, and systemic arterial oxygen saturations were lower with smaller defects $(p=0.03)$. There was a significant fall in saturation from the time of septostomy to the time of the second study even in the presence of large defects $(p<0.05)$. Left atrial, right atrial, and pulmonary artery pressures were all significantly lower in the presence of large defects $(p<0.05)$. 


\section{SECOND STUDY}

A second catheterisation was performed at an earlier age in failures $(p<0.001)$, so that haemodynamic data are not strictly comparable between failure and success groups. Systemic arterial oxygen saturation was lower in failures $(p<0.001)$, and before 1976 haemoglobin concentration was lower in failures than successes $(p=0.037)$ but not for 1976-79 $(p=0.5)$. There were many missing pressure data, making interpretation difficult. Pulmonary artery pressure tended to be higher in the failure group, but this was not quite significant at the $5 \%$ level.

Thrombosis of the inferior vena cava or its major branches and cerebrovascular accidents grouped together were associated with poor survival at 6 months $(p=0 \cdot 008)$. There was no association between thrombosis and either haemoglobin concentration or systemic arterial oxygen saturation at the second study.

\section{MORBIDITY, MORTALITY, AND FAILURE}

ASSOCIATED WITH LARGE BALLOONS

Of 41 infants who underwent septostomy with balloon volumes between 3.5 and $6 \mathrm{ml}$, two had transiently abnormal neurological signs within one week of septostomy with subsequent normal developmental progress. There were no cases of atrial rupture. Two deaths occurred within one month of septostomy; one infant was moribund before septostomy and died within 24 hours of the procedure; the other developed necrotising enterocolitis. Thirty eight infants were alive at 3 years of age and one had died suddenly at 7 months of age.

Four infants with simple transposition underwent repeat septostomy between 2 weeks and 4 months of age, and all four are alive after definitive surgery between 11 and 14 months of age. Another infant successfully tolerated definitive surgery at 4 months of age.

\section{Discussion}

Early survival of infants with transposition of the great arteries has been dramatically improved by the palliative technique of balloon atrial septostomy. Nevertheless, a considerable cumulative morbidity and mortality up to the time of definitive surgery has been seen despite this procedure. ${ }^{4-20}$ More recent reports reflect an improving outlook for the first year of life after palliation.2122 At our centre the use since 1976 of a new generation of balloon catheters, capable of dilating to balloon volumes of $4 \mathrm{ml}$ without distortion of their configuration, ${ }^{24}$ coincided with an improving outcome for these infants. Before 1976 catheters in use had a maximum effective balloon capacity of $3 \mathrm{ml}$, further dilatation leading to elonga- tion rather than an increase in transverse diameter. Many factors have probably contributed to the recent improvement in early survival. Nevertheless, maximum balloon volume was significantly associated with failure of septostomy regardless of year, and there is little doubt that the use of larger balloons has contributed appreciably to the improved survival in the later years of the study. Larger balloon volumes were also associated with larger defects seen subsequently at surgery or necropsy; defect size was itself significantly associated with success of palliation and survival to 6 months of age.

Thus six months' palliation from septostomy in most cases depends on the production of a defect of adequate size, which from our data usually means a defect of $\geqslant 15 \mathrm{~mm}$ diameter as measured subsequently at surgery. Production of a large defect at septostomy does not, however, guarantee its permanence. The importance of technique in producing an adequate defect has been emphasised ${ }^{25} 26$; first pull volumes of under $2 \mathrm{ml}$ may lead to stretching rather than tearing of the septum with good immediate results but inadequate long term palliation. ${ }^{26}$ Data on whether first pull or maximum balloon volumes or other operative techniques determine adequate tearing of the atrial septum are sparse; Hawker et al found that success and failure groups had been treated with similar first pull diameters of about $12 \mathrm{~mm},{ }^{15}$ but the balloons were of not more than $3 \mathrm{ml}$ effective volume. Our data cannot differentiate the effects of first pull and maximum volumes, although the latter appears to have more influence on the success of the procedure.

The success rate was highest with maximum volumes of over $3 \mathrm{ml}$ and first pull volumes of at least 2 $\mathrm{ml}$, using catheters that retain a roughly spherical configuration at these volumes. That stretching and subsequent shrinkage of the atrial septum do occur after attempts at balloon septostomy is suggested by the fact that failures and successes had similar changes in systemic arterial oxygen saturations after septostomy, but failures had relatively sharp falls in saturation to subsequent study with smaller defects measured at surgery or necropsy. Furthermore, many such infants experience long lasting palliation after a repeat septostomy. Rarely, shrinkage of an atrial defect may occur after atrial septectomy. ${ }^{27}$

The insertion of a suitably sized catheter via a femoral vein is occasionally difficult. A further difficulty may be excessive resistance ${ }^{26}$ to passage of the balloon through the atrial septum. Nevertheless, Henry et al used balloon volumes of over $3 \mathrm{ml}$ in 42 of 43 infants and produced defects of $>15 \mathrm{~mm}$ in 27 , $10-15 \mathrm{~mm}$ in four, and $<10 \mathrm{~mm}$ in four. ${ }^{21}$ Blade atrial septostomy ${ }^{29}$ is available for infants in whom the atrial septum may be too tough to tear.

Concern has been expressed about the possible 
hazard of atrial rupture during septostomy with large balloons. ${ }^{30}$ In our experience, this complication is independent of balloon volumes of up to $6 \mathrm{ml}$; indeed the use of balloon volumes of between 3.5 and $6 \mathrm{ml}$ has not been associated with excessive incidence of any complication compared with smaller balloons.

Interpretation of the association between other variables and failure of septostomy is hampered by the unavailability of data on all cases, particularly findings at the second study. The accuracy of diagnostic categorisation of associated lesions such as ventricular septal defect and left ventricular outflow tract obstruction is also open to doubt in view of the discrepancy in the diagnostic frequency of these lesions between group years. Our data do, however, reflect the malignant nature of even a small persistent ductus arteriosus cited by others. ${ }^{4} 22$ There was, however, a significantly lower mortality associated with this lesion in 1976-79, suggesting improved management. We cannot deduce whether the presence of a large atrial defect modifies the adverse effects of a persistent ductus, such as by reducing right ventricular overload, although large defects were generally associated with lower pulmonary artery pressures than were small defects.

The timing of definitive surgery for infants with transposition of the great arteries will depend on the risks of early surgery and the risks of waiting to the optimal age for surgery in each case. Relatively poor survival data after balloon atrial septostomy have led some centres to advocate elective definitive surgery within the first weeks of life ${ }^{1128}$ or in the presence of adverse factors. ${ }^{22}$ Our data suggest that, given the benefit of modern medical management, most of these infants may survive to elective surgery beyond 6 months of age in the presence of a large atrial defect. Failure of septostomy to allow survival beyond the first 6 months of life may be regarded as either failure to produce a long lasting large defect or failure in the presence of such a defect. Echocardiography ${ }^{31}$ allows failure to be defined non-invasively.

Consistent production of such a defect requires the use of balloon catheters capable of expanding to adequate volumes without distortion of their configuration; such modern balloons have a partly suboid rather than spherical configuration, which may favour tearing of the atrial septum rather than stretching of the interatrial opening. Interpretation of data on the fate of infants with transposition of the great arteries after balloon atrial septostomy should take into account the type of balloon used.

We recommend that balloon septostomy should be performed with first pull volumes of $2-2.5 \mathrm{ml}$; subsequent pulls should be performed with increasing volumes leading to a maximum of $4-4.5 \mathrm{ml}$. Greater volumes are not usually necessary and may increase the risk of the procedure.

\section{References}

1 Piccoli GP, Wilkinson JL, Arnold R, Musumeci F, Hamilton DI. Appraisal of the Mustard procedure for the physiological correction of "simple" transposition of the great arteries. 7 Thorac Cardiovasc Surg 1981; 82: 436-46

2 Liebman J, Cullum L, Belloc NB. Natural history of transposition of the great arteries. Anatomy and birth and death characteristics. Circulation 1969; 40: 237-62.

3 Rashkind WJ, Miller WW. Creation of an atrial septal defect without thoracotomy. FAMA 1966; 196: 991-2.

4 Rashkind WJ. Transposition of the great arteries before the Mustard operation. Ten years experience with balloon atrioseptostomy at the Children's Hospital of Philadelphia. In: Kidd BSL, Rowe RD, eds. The child with congenital heart disease after surgery. Mount Kisco, NY: Futura, 1976: 149-52.

5 Singh SP, Astley R, Burrows FGO. Balloon septostomy for transposition of the great arteries. Br Heart $\mathcal{F} 1969$; 31: 722-6.

6 Venables AW. Balloon atrial septostomy in complete transposition of great arteries in infancy. Br Heart $\mathcal{F} 1970$; 32: 61-5.

7 Plauth WHJ Jr, Nadas AS, Bernhard WF, Fyler DC. Changing hemodynamics in patients with transposition of the great arteries. Circulation 1970; 42: 131-42.

8 Muster AJ, Levin SE, Cole RB, Paul MH. The (modified) history of transposition of the great arteries following nonsurgical atrial septostomy [Abstract]. Am $\mathcal{F}$ Cardiol 1970; 25: 118.

9 Baker F, Baker L, Zoltun R, Zuberbuhler JR. Effectiveness of the Rashkind procedure in transposition of the great arteries in infants. Circulation 1971; 43 (suppl I): $1-6$.

10 Parsons CG, Astley R, Burrows FGO, Singh SP. Transposition of great arteries: a study of 65 infants followed for 1-14 years after balloon septostomy. Br Heart $\mathcal{f} 1971$; 33: $725-31$.

11 Clarkson PM, Barratt-Boyes BG, Neutze JM, Lowe JB. Results over a ten-year period of palliation followed by corrective surgery for complete transposition of the great arteries. Circulation 1972; 45: 1251-8.

12 Tynan M. Survival of infants with transposition of the great arteries after balloon atrial septostomy. Lancet 1971; i: 621-3.

13 Neches WH, Mullins CE, McNamara DG. The infant with transposition of the great arteries. 2. Results of balloon atrial septostomy: Am Heart f 1972; 84: 603-9.

14 Parisi L, Fyler DC. Management of transposition of the great arteries in New England [Abstract]. Am $\mathcal{F}$ Cardiol 1973; 31: 151 .

15 Hawker RE, Krovetz LJ, Rowe RD. An analysis of prognostic factors in the outcome of balloon atrial septostomy for transposition of the great arteries. Fohn Hopkins Med f 1974; 134: 95-106.

16 Kidd BSL. The fate of children with transposition of the great arteries following balloon atrial septostomy. In Kidd BSL, Rowe RD, eds. The child with congenital heart 
disease after surgery. New York: Futura, 1976: 153-622.

17 Vlad P, Lambert EC. Late results of Rashkind's balloon atrial septostomy in transposition. In: Kirklin J, ed. Advances in cardiovascular surgery. New York: Grune \& Stratton, 1973: 29-36.

18 Lam LKT, McCann P, Ward OC. Transposition of the great arteries in the newborn: a three year survey. Ir $\mathcal{F}$ Med Sci 1978; 147: 267-71.

19 Gutgesell HP, Garson A, McNamara DG. Prognosis for the newborn with transposition of the great arteries. $\mathrm{Am}$ f Cardiol 1979; 44: 96-100.

20 Fyler DC, ed. Report of the New England Regional Cardiac Program. Transposition of the great arteries. Pediatrics 1980; 65: 422-8.

21 Henry CG, Goldring D, Hartmann AF, Weldon CS, Strauss AW. Treatment of d-transposition of the great arteries: management of hypoxemia after balloon atrial septostomy. Am f Cardiol 1981; 47: 299-306.

22 Leanage R, Agnetti A, Graham G, Taylor J, Macartney FJ. Factors influencing survival after balloon atrial septostomy for transposition of great arteries. $\mathrm{Br} \mathrm{Heart} \mathrm{f}$ 1981; 45: 559-72.

23 Cox DR. The analysis of binary data. London: Methuen, 1970.

24 Miller Balloon Atrioseptostomy Catheter-technical information sheet. Santa Ana: Edwards Laboratories, 1980.

25 Rashkind WJ. Palliative procedures for transposition of the great arteries. Br Heart $\mathcal{F}$ 1971; 33 (suppl): 69-72.

26 Meng CCL, Wells CR, Valdes-Dapena M, Arey JB, Black IFS, O'Riordan AC. The anatomy of the foramen ovale in relation to balloon atrial septostomy [Abstract]. Paediatr Res 1973; 7: 304.

27 Litwin SB, Plauth WH Jr, Jones JE, Bernhard WF. Appraisal of surgical atrial septectomy for transposition of the great arteries. Circulation 1971; 43 (suppl I): 7-10.

28 Kawabori I, Guntheroth WG, Morgan BC, Hohri H, Dillard DH. Surgical correction in infancy to reduce mortality in transposition of the great arteries. Pediatrics 1977; 60: 83-5.

29 Park SC, Neches WH, Zuberbuhler JR, et al. Clinical use of blade atrial septostomy. Circulation 1978; 58: 600-6.

30 Sondheimer HM, Kavey REW, Blackman MS. Fatal over-distension of atrioseptostomy catheter. Pediatr Cardiol 1982; 2: 255-7.

31 Bierman FZ, Williams RG. Subxiphoid two-dimensional imaging of the interatrial septum in infants and neonates with congenital heart disease. Circulation 1979; 60: 80 90. 